JOURNAL OF BIOMEDICAL RESEARCH \& CLINICAL

PRACTICE

Original Article

\title{
Informed Consent For Anaesthesia: Are Our Patients Well Informed?
}

Embu HY, ${ }^{*}$ Yilkudi MG, ${ }^{1}$ Nuhu SI.

Department. of Anaesthesia, Jos University Teaching Hospital, P.M.B 2076, Jos, Nigeria.

${ }^{1}$ Department. of surgery, University of Abuja Teaching Hospital, Gwagwalada, FCT.

\section{ABSTRACT}

*Corresponding Author: Dr. Henry Y. Embu, Dept. of Anaesthesia, Jos University Teaching Hospital, P.M.B. 2076, Jos. Nigeria. Tel: +2348037193834. Email: embuy@yahoo.com

Patients have the right to be properly informed about procedures to be undertaken on them so that they could make informed decisions. This study was done at the Jos University Teaching Hospital and the University of Abuja Teaching Hospital. Questionnaires on informed consent were administered postoperatively on patients who had undergone elective surgeries under various forms of anaesthesia. The questionnaires sought to find out how much information patients were given about their anaesthesia and how satisfied they were with the information given. 148 patients were interviewed. The mean age was $34.8 \pm 13.8$ years and the male: female ratio was 1:1.8. Ninety-eight $(66.22 \%)$ of the procedures were done under general anaesthesia and 50(33.78\%) under regional anaesthesia. $104(70.27 \%)$ were told about the type of anaesthesia to be used. Thirty-eight $(25.68 \%)$ were not told of the possible side effects. Eighty-six $(58.1 \%)$ understood the information given. $131(88.51 \%)$ believed it was necessary to be given information about the anaesthesia. Postoperative pain management was discussed with $10(6.76 \%)$ of respondents. $104(70.27 \%)$ expressed satisfaction with the information given. Information about anaesthesia was given by residents in anaesthesia in $62.16 \%$ of cases, by consultant anaesthetists in $8.78 \%$ cases, by surgeons in $10.81 \%$ of cases and by house officers and nurses in $14.19 \%$ of cases. Majority of patients would like information about their anaesthesia procedures but were inadequately informed. Consent for anaesthesia is often obtained by junior residents who have had little training in this aspect. Training on informed consent should be part of the residency program.

Keywords: Informed consent, Anaesthesia, Patients.

2018 Joumal Impact Factor: 1.10

Print ISSN: 2636-7378| Online ISSN: 2651-5865

\section{INTRODUCTION}

$\mathrm{I}^{\mathrm{n}}$ nformed consent has gradually evolved from its form in the past when it was mainly to protect the doctor to its current form in which it is more patient centered. Though currently the emphasis is on providing information that would enable patients make informed decisions there is still difficulty in reaching a consensus as to how much information to give the patient. ${ }^{1,2}$ In reality both physician-based and patient-centered informed consent practices still exist in different centres. In the physician-based practice the physician has the discretion to decide how much information to give the patients while the patient-centered practice requires that the consent process must provide the risks, benefits and alternatives that a reasonable patient would want to know. ${ }^{3,4}$ Even though many centres attempt to work out a middle point between the two where decision making is shared, it appears in our environment the physician-based practice is more prevalent. ${ }^{5}$ Patients' need for information may also vary as many may not feel the need for more information than what is given while on the other hand, on many occasions patients' need for information is often underestimated. ${ }^{6,7}$

A search of the literature revealed that most previous studies on informed consent in our environment bordered on surgical 
consent while there is paucity of studies involving consent for anaesthesia. ${ }^{8,9,10}$ Our study is designed to review the practices of informed consent for anaesthesia among in-patients who had elective surgeries in two tertiary hospitals in Nigeria. We set out to determine the type of information the patients were given before anaesthesia and whether they considered these information important. We also wanted to know if the patients were satisfied with the informed consent process.

\section{MATERIALS AND METHODS}

The study was carried out at the Jos University Teaching Hospital (JUTH) and the University of Abuja Teaching Hospital (UATH) between January and March 2014. Approvals of institutional ethics committees were obtained. JUTH and UATH are tertiary hospitals located in north central Nigeria. JUTH has a 530 bed capacity with four theatre suites for elective cases and one for emergencies while UATH is a 200 beds facility. The study is a cross sectional study and convenience sampling was used. Adult patients who underwent elective surgical procedures were approached postoperatively to participate in the study. Patients who were below 18 years, ambulatory surgical and unconscious patients or patients who could not adequately communicate were excluded from the study.

\section{Questionnaire Design and Deployment}

Questionnaires were designed following a search of the literature and randomly administered to adult patients (18 to 65 years) after consent was obtained from the patients. The patients had undergone elective surgeries under different forms of anaesthesia and the questionnaires were administered postoperatively.

The questionnaires were administered by self-administration in educated respondents while it was by interview in the uneducated respondents and two of the authors with two assistants carried out the interviews. This was done one to four days postoperatively. The personnel that managed the patients' anaesthesia were usually not present during the interview.

The questionnaire was designed among other things to capture the respondents' demographic details and type of anaesthesia. It also sought to know the type of information given to patient concerning his/her anaesthesia and whether the patient considered the information important. Other things of interest in the questionnaire included the timing of consent, who obtained consent from the patient and whether the patient was satisfied with the process by which the consent was obtained. The data was presented as frequencies, proportions and means. Epi info version 7 was used for data analysis. $\mathrm{P}-$ value $<0.05$ was considered statistically significant.

\section{RESULTS}

A total of 148 patients completed the questionnaires out of 200 which were deployed giving a completion rate of $74 \%$. Eighty (54.05\%) were females and 68(45.95\%) were males with a male: female ratio of $1: 1.8$. The mean age of the patients was $34.81 \pm 13.84$ with a range of 18 to 66 years. Ninety eight (66.22\%) had general anaesthesia and 50(33.78\%) had regional anaesthesia (spinal anesthesia or epidural anaesthesia) Table 1. Most of the patients $126(85.14 \%)$ knew the diagnosis of their ailment while 104(70.27\%) were told the type of anaesthesia that would be used for their surgery. Only 38(25.68\%) were told about possible complications of anaesthesia and 29(19.59\%) were told about alternative forms of anaesthesia that could be used Table 2. Postoperative pain management was discussed with $10(6.76 \%)$ of patients. Fifty three (35.81\%) patients said they were given the opportunity to ask questions. Most patients $131(88.51 \%)$ felt it was necessary to be given information on the type of anaesthesia and 136(91.89\%) thought it was necessary to be told about alternative forms of anaesthesia. A greater number 101(68.24\%) also wanted to be told about postoperative pain management Table 3. Majority i.e. $101(68.24 \%)$ of the consent were obtained a day before surgery while $20(13.51 \%)$ were obtained on the morning of surgery and 6(4.05\%) in the operating room Table 4. In most cases $92(62.16 \%)$ consent were obtained by resident doctors in anaesthesia and only in 13(8.78\%) cases was it obtained by consultant anaesthetists. In 37(25.0\%) cases, consent was obtained by non-anaesthetists while in 6(4.06\%) the patients did not know the status/identity of the person obtaining the consent.

Fifty two (35.14\%) patients expressed little or no understanding of the information given while $86(64.84 \%)$ had a good understanding of the information Table 5. A greater number i.e. 104(70.27\%) of the patients were satisfied with the consent process. Literacy level of the patients was not related to understanding of the information $(\mathrm{p}=0.959)$ and also not related to satisfaction with the process of consent $(p=0.762)$. 
Table 1. Demographics and Type of Anaesthesia

\begin{tabular}{cll}
\hline Demographics & & $\mathbf{N}(\%)$ \\
\hline \multicolumn{1}{c}{ Gender } & $\mathrm{F}$ & $80(54.05)$ \\
& $\mathrm{M}$ & $68(45.95)$ \\
Age & (Mean $\pm \mathrm{SD})$ & $34.81 \pm 13.84$ \\
& & \\
Educational level & Nil formal & $16(10.81)$ \\
& Primary & $18(12.16)$ \\
& Secondary & $50(33.78)$ \\
Type of Anaesthesia & Tertiary & $60(40.54)$ \\
& & \\
& GA & $98(66.22)$ \\
& Regional & $50(33.78)$ \\
\hline
\end{tabular}

Table 2. Information given to patients about Anaesthesia

\begin{tabular}{lll}
\hline Information sought & Yes & No \\
& $\mathrm{n}(\%)$ & $\mathrm{n}(\%)$ \\
\hline Type of Anaesthesia & $104(70.27)$ & $44(29.73)$ \\
Alternative anaesthesia & $29(19.59)$ & $119(80.41)$ \\
Complications of anaesthesia & $38(25.68)$ & $110(74.32)$ \\
Postoperative pain mgt & $10(6.76)$ & $138(93.24)$ \\
Allowed to ask questions? & $53(35.81)$ & $95(64.19)$ \\
Diagnosis & $126(85.14)$ & $22(14.86)$ \\
\hline
\end{tabular}

Table 3. Necessity for information

\begin{tabular}{lll}
\hline Was any of this information necessary? & $\begin{array}{l}\text { Yes } \\
\mathrm{n}(\%)\end{array}$ & $\begin{array}{l}\text { No } \\
\mathrm{n}(\%)\end{array}$ \\
\hline Type of Anaesthesia & $131(88.51)$ & $17(11.49)$ \\
Alternative anaesthesia & $136(91.89)$ & $12(8.11)$ \\
Possible complications & $116(78.38)$ & $32(21.62)$ \\
Postoperative pain mgt & $101(68.24)$ & $47(31.76)$ \\
\hline
\end{tabular}

Table 4. Timing of consent and personnel who obtained consent

\begin{tabular}{lll}
\hline Timing of consent & $\mathrm{n}(\%)$ \\
\hline & $>1$ day before surgery & $21(14.19)$ \\
& A day before surgery & $101(68.24)$ \\
& On the morning of surgery & $20(13.51)$ \\
& In the operating room & $6(4.06)$ \\
$\begin{array}{l}\text { Personnel who gave } \\
\text { information }\end{array}$ & \\
& & \\
& Consultant Anaesthetist & $13(8.78)$ \\
& Resident in anaesthesia & $92(62.16)$ \\
& Surgeon & $16(10.81)$ \\
& House officer & $12(8.11)$ \\
& Nurse & $9(6.08)$ \\
& Don't know & $6(4.06)$ \\
\hline
\end{tabular}

Table 5. Patients' understanding and satisfaction with informed consent process

\begin{tabular}{lll}
\hline Patients' understanding & $\mathrm{n}(\%)$ \\
\hline & Did not understand & $24(16.22)$ \\
& Understood a little & $28(18.92)$ \\
& Understood well & $68(45.94)$ \\
& Understood perfectly & $28(18.92)$ \\
Patients' satisfaction & & \\
& Satisfied & $104(70.27)$ \\
& Not satisfied & $44(29.73)$ \\
\hline
\end{tabular}

\section{DISCUSSION}

In the two institutions where the patients were interviewed the anaesthesia consent form is incorporated into the surgical consent form and not a separate document. The form is often signed in the presence of the surgeon or sometimes a nurse. The form does not contain any information about the intended surgery or anaesthesia and it is expected that all necessary information concerning the proposed procedures would have been given to the patient by the doctors involved prior to signing the form.

We found that majority of our patients knew the diagnosis of their ailment and $70.27 \%$ were told the type of anaesthesia to be used. Nnabugwu et $a l^{10}$ in a study on surgical patients in Enugu, South East Nigeria observed that $78.3 \%$ of the respondents recalled the nature of their disease condition while Jawaid et $a l^{11}$ from Pakistan reported that $87.7 \%$ of patients were informed about their condition and the nature of surgery they were to undergo. On the other hand Jawaid et al also reported that $72.5 \%$ of their respondents were aware of the type of anaesthesia to be given.

To the best of our knowledge there are no published guidelines for obtaining consent for anaesthesia in Nigeria unlike in other climes. ${ }^{12}$ However the general rule for obtaining consent requires that the health care provider provides the patient with information about the nature of the proposed treatment among other things.

The professional conduct of medical doctors in Nigeria is guided by the code of medical ethics in Nigeria and rule 19 of part A states that in obtaining informed consent the benefits and risks of a procedure must be explained to a patient. ${ }^{13}$ However, only $25.68 \%$ of our respondents were told about the possible complications of anaesthesia. This trend appears to be common practice as Nnabugwu et al reported that $21.7 \%$ of their respondents were informed about the risks associated with the procedures while in the study by Jawaid et al only $4.9 \%$ said they were aware of the complications of anaesthesia. 
In a study among anaesthetists in Lagos, Nigeria $51.79 \%$ agreed that they would disclose all major risks with incidence > $1 / 20$ suggesting that about half the anaesthetists would only disclose major complications that were common than rare ones. ${ }^{14}$ In the same study $23.21 \%$ of anaesthetists felt that discussing risks during informed consent may dissuade the patient from undergoing a procedure that may benefit them. This was similar to what was reported by Jamjoom et $a l^{15}$ in a study from the UK.

Despite the fact that $91.89 \%$ of respondents wanted to know about the anaesthesia alternatives only $19.59 \%$ said that alternatives were discussed with them. Informing patients about alternatives is pertinent although Keating et al reported that treatment alternatives is one aspect of informed consent that is often forgotten by patients. ${ }^{16}$ Patients are also expected to be told of the effects or consequences of having no treatment. In the court case reported by Pascarella et al, ${ }^{17}$ the failure of the anaesthetist to discuss alternatives to general anaesthesia with the patient was a major issue raised by the prosecution.

Very few patients were told about postoperative pain management and often this information was only offered when patients specifically asked about it. Only $35.81 \%$ of respondents said they were given the opportunity to ask questions during the process of informed consent. This is similar to what was obtained in the study by Jawaid et al. ${ }^{11}$ In our hospitals postoperative pain management is usually handled by the surgeons and it appears the patients were also not given the information by surgeons.

The timing of when information is given to the patient is also very important and it is thought that patients for elective surgeries should be provided information before admission preferably at pre-assessment or at the time of booking. ${ }^{12}$ This should give the patient sufficient time to consider the information before making a decision. Providing a patient with new information in the anaesthetic room or immediately before induction as happened with a few of our patients is not acceptable practice.

Most of the informed consent process in our study was conducted by resident doctors, usually junior residents. Studies have shown that junior doctors are frequently in charge of the informed consent process and are often not likely to provide enough information concerning the nature of treatment, risks, alternatives and benefits. ${ }^{18,19}$ In $10.81 \%$ of our patients consent for anaesthesia was obtained by surgeons and it is obvious that surgeons are not best suited to give information concerning anaesthesia. ${ }^{20}$ Anaesthesia is a different specialty with its own unique set of risks/complications that are better understood and explained by the anaesthetist.

A good number of our patients (35.14\%) expressed little or no understanding of the consent process. Similar findings in other studies showed that many patients generally have difficulty understanding medical information. ${ }^{21,22}$ In another study by Tait et $a l,{ }^{23}$ only $0.8 \%$ of respondents reported being unclear with preoperative anaesthesia information they received and $18.4 \%$ believed there was too little information. They also found that understanding was not related to race or ethnicity. Unlike in our study, some other studies reported that inability to understand information given was highest among respondents with no formal education. ${ }^{24}$ It is our belief that so long as the anaesthetist is able to communicate in the language the patient understands there is generally a good appreciation of the information delivered.

Surprisingly despite what we considered insufficient delivery of information, a greater proportion of the respondents expressed satisfaction with the process of informed consent. Some studies also reported a high level of satisfacton ${ }^{10,23}$ though unlike in our study some reported a much higher satisfaction among the more educated group of respondents. ${ }^{10}$ Information obtained from the patients was one to five days postoperatively and this may be affected by the patients' recall. Our study was not a randomized study and rather used convenience sampling and was carried out in two institutions in north central Nigeria and as such may not be representative of what generally happens across the region or nation.

\section{CONCLUSION}

Even though our patients expressed a good level of satisfaction we found a number of inadequacies with the process of informed consent for anaesthesia in our institutions. These inadequacies were most profound in the areas of not providing information about complications, alternatives and postoperative pain management though most patients wanted these information.

\section{RECOMIMENDATIONS}

A separate properly designed anaesthesia consent form will enhance the understanding that signing a surgical consent form does not cover for anaesthesia and will also ensure a better documentation of professional discussion with the patient. 
Since most of our anaesthesia informed consent processes are handled by junior doctors they should receive appropriate training and this should be done early in their training program. Senior doctors should also be encouraged to be more involved in providing information in order to improve the quality of the process.

\section{Conflict of Interest}

None declared.

\section{REFERENCE}

1. Akkad A, Jackson C, Kenya S. Patients perception of written consent questionnaire study. BMJ (online). 2006;333(767):528. Available on doi:10.1136bmj38922.516204.55 (accessed 12/12/2017)

2. Bernet JL, Peterson LM. Patient - centered informed consent in surgical practice. Arch Surg. 2006;14(1):186-192

3. King JS, Moulton BW. Rethinking informed consent: the case for shared medical decision-making. Am J Law Med. 2006;32(4):429501

4. Michota FA, Doually MJ. Medicolegal issues in perioperative medicine. Lessons from real cases. ClevClin J Med. 2009;76(suppl 4):5119-5125

5. King JS, Moulton BW. Rethinking informed consent: the case for shared medical decision-making. Am J Law Med. 2006;32(4):429501

6. Ghulam AT, Kesler M, Bachman IM. Patients satisfaction with the preoperative consent procedure: a multicenter questionnaire survey in Switzerland. Mayo ClinPrac. 2006;81(3):307-312

7. Pesudov K, Luscombe CK, Coster DJ. Recall from informed consent counseling for cataract surgery. J Law Med. 2006;13(4):496-504

8. Ezeoma ER, Marshall PA. Informed consent practices in Nigeria. Developing World Bioethics (online). 2008;1471-8847 Available on doi:10.1111/j.1471-8847.2008.0024.x (accessed 22/10/2017)

9. Atanda OO, Owonikoko KM, Adeniji AO. Pre-operative written consent in Nigeria: How informed are our patients? J Med MedScie. 2013;4(8):307-310

10. Nnabugwu II, Ugwumba FO, Udeh EI, Ayimba SK, Ozoemena OF. Informed consent for clinical treatment in low income setting: evaluating the relationship between satisfying consent and extent of recall of consent information. BMC Medical Ethics (online). 2017;18:69. Availabe on doi10.1186/s12910-017-0227-4. (Accessed $5 / 12 / 2017)$

11. Jawaid M, Farhan M, Masood Z, Husnain SMN. Preoperative informed consent: is it truly informed? Iranian J Publ Health. 2012;41(9):25-30
12. Yentis SM, Hartle AJ, Barker IR, Barker P, Bogod DG, CluttonBrock TH et al. Association of Anaesthetists of Great Britain and Ireland AAGBI: Consent for Anaesthesia. Anaesthesia. 2017;72:93105

13. Medical and Dental Council of Nigeria. Code of Ethics in Nigeria (Rules of Professional Conduct for Medical and Dental Practitioners). 2004;25-30

14. Olatosi JO, Adekola OO, Anaegbu NC, Adesida A, Rotimi MK. Anaesthetists attitudes and practice of informed consent in Nigeria. J West AfrColl Surg. 2016;6(4):83-103

15. Jamjoon AAB, White S, Walton SM, Hardman JG, Moppett IK. Anaesthetists' and surgeons' attitudes towards informed consent in the UK: an observational study. BMC Medical Ethics (online). 2010;11:2. Available on http//www.biomedcentral.com/14726939/11/2 (Accessed 12/11/2017)

16. Keating NL, Weeks JC, Borbas C. treatment of early stage breast cancer: Do surgeons and patients agree whether treatment options are discussed? Breast Cancer Res Treat. 2003;79(2):225-231

17. Pascarella MR, Walls JD, Liu R, Chen L. Anesthesia providers are obligated to give patients the alternatives to general anaesthesia when obtaining informed consent. TranslPerioper Pain Med. 2014;1(2):5-8

18. Pleat JM, Dunkin CS, Davies CE. Prospective survey of factors affecting risk discussion during consent in a surgical specialty. Br J Surg. 2004;91(10):1377-1380

19. Angelos P, Derosa DA, Bentram D. residents seeking informed consent: are they adequately knowledgeable? Curr Surg. 2002;59(1):115-118

20. Marcucci C, Seagull FJ, Loreck D, Bourke DL, Sandson NB. Capacity to give surgical consent does not imply capacity to give anaesthesia consent: implications for anesthesiologists. Anesth Analg. 2010;110(2):596-600

21. Nadeau D, Rich J, Brietzke S. Informed consent in paediatric surgery: Do parents understand the risks? Arch Otolaryngol Head Neck Surg. 2010;136:265-269

22. Langdon I, Hardin R, Learmonth I. Informed consent fr total hip arthroplasty: does a written information sheet improve recall by patients? Am R Coll Surg Engl. 2002;84:404-408

23. Tait AR, Voepel-Lewis T, Gauger V. Parental recall of anesthesia information: informing the practice of informed consent. Anesth Analg. 2011;112(4):918-923

24. Agu KA, Obi EI, Eze BI, Okenwa WO. Attitude toward informed consent practice in a developing country: a community-based assessment of the role of educational status. BMC Medical Ethics (online). 2014;15:77. Available on http://www.biomedcentral.com/1472-6939/15/77 (Accessed 12/01/2018) 